\title{
Carcinoma Metastasis - An Approach to Models
}

\section{Haakon Skogseth ${ }^{1 *}$, Kåre E. Tvedt' ${ }^{1}$ and Jostein Halgunset ${ }^{1,2}$}

${ }^{1}$ Department of Laboratory Medicine, Children's and Women's Health, Faculty of Medicine, Norwegian University of Science University, 7006 Trondheim, Norway ${ }^{2}$ Department of Pathology and Medical Genetics, St. Olav's Hospital, 7006 Trondheim, Norway

\begin{abstract}
Background: Epithelium is separated from other tissues in the body by the basal membrane. When respecting this boundary, atypical epithelial growth does not cause serious illness in most cases. Therefore, carcinoma in situ is considered to be a non-malignant condition. However, the situation is quite different if the epithelial cells do not respect the natural boundaries in the tissue, a condition that is often referred to as cancer. Uncontrolled invasive growth is indeed the main characteristic of malignancy, and metastasis is in most cases the reason why cancer patients die.
\end{abstract}

Materials and methods: The purpose of this article is to highlight how carcinoma cells, nature, can be classified in three steps, in respect to the first local infiltration of malignant epithelium. The literature referred to is selected on the basis that the views advocated are not controversial, and not represent individual findings. Moreover, some considerations are based on the authors own experience in clinical and molecular basic research.

Results: The main characteristics of invasive cellular behavior are modified adhesion and a transition from fixed cells to a migratory phenotype. Invasion is made possible by the degradation of extracellular components. We only know fragments of the gene and phenotypic changes that enable cancers origin of behavior, but there is evidence that chemokines play a central role in the directional spread of motile cells. However, the most common characteristic of carcinoma cells is their loss of cell polarity.

Interpretation: The complexity of multicellular organisms is staggering. Artificial and highly simplified model systems are therefore cancer researcher's most important tools. To be significant, such results must be translated and verified to the in vivo situation. In addition, generality in cancer research finding must be given greater importance, since individual results, not can form the basis for new treatment regimes. Today's biggest challenge for researchers is therefore to be able to collate the enormous diversity of molecular biological knowledge that daily runs.

\section{Keywords: Carcinoma; Metastasis; Invasion; Adhesion; Motility}

\section{Introduction}

Cancer occurs in different cell types. It is classified according to which tissue the cells are derived from. Sarcomas arise in connective tissue and muscle, while leukemia, lymphoma and myeloma occur in blood and immune cells. However, about $90 \%$ of all cancer cases in humans are epithelial, the carcinomas. Although the lack of growth control is common to the malignant phenotype, this characteristic could be found both in benign and malignant tumors. The really critical question is whether the tumor respects the normal anatomical boundaries or whether the cells infiltrate the surrounding environment, made visible by the fact that $90 \%$ of deaths of patients with solid tumors are attributed to local invasion and distant metastasis [1-6]. Moreover, in practice and very often, it is challenging to assess the malignant potential of cancer cells of non-epithelial origin, but in epithelial tumors the diagnostic main criterion which is used to distinguish between a malignant and a benign lesion, is whether tumor cells grow into the surrounding tissue or not. Since tumor cells in carcinomas arise from epithelium, such diagnostic practice is based on the normal tissue morphology taken together with the seen abnormalities, which is considered to be a benign change or a precursor to malignancy.

Epithelium forms the thin, organized layers of cells that cover inner and superficial body surfaces, and form barriers of various thicknesses between other tissue types. The basoapical organization of monolayered epithelia is defined by the presence of hemidesmosomes at the basal cellular pole, where the cell makes contacts with the basement membrane. As described initially by Farquhar and Palade, the lateral cell to cell contacts of the polarity axis include, from apical to basal locations, the tight junctions (or zonula occludens), the adherens junctions (or zonula adherens), and the desmosomes. Such polarization is a prerequisite for cellular adhesion and intercellular communication pathways [7]. This polarization is changed or lost in the malignant pathology state, typically characterized by the change from firmly anchored epithelial cells to cells with weak binding to neighboring cells and extracellular matrix, and which migrate individually [8]. Moreover, malignant epithelial cells are characterized by directional movement, which implies degradation of surrounding proteins, such as the underlying basal lamina. Thus, the first local spread of malignant epithelial cells consists of three steps: modified cellular adhesion, local proteolysis of the extracellular matrix, and a directional movement through surrounding tissue [9]. Yet, until today, the carcinoma spread pattern is based on empirical data rather than cellular and physiological explanation models. This may seem strange,

*Corresponding author: Haakon Skogseth, Department of Laboratory Medicine, Children's and Women's Health, Faculty of Medicine, Norwegian University of Science and Technology, 7006 Trondheim, Norway, Tel: 725730 81, 90958493; E-mail: haakon.skogseth@ntnu.no

Received July 05, 2011; Accepted September 04, 2011; Published September 07, 2011

Citation: Skogseth H, Tvedt KE, Halgunset J (2011) Carcinoma Metastasis - An Approach to Models. J Carcinogene Mutagene 2:119. doi:10.4172/21572518.1000119

Copyright: (c) 2011 Skogseth $\mathrm{H}$, et al. This is an open-access article distributed under the terms of the Creative Commons Attribution License, which permits unrestricted use, distribution, and reproduction in any medium, provided the original author and source are credited. 
since over the past decade, quite a lot of theories have been put forward to explain carcinogenesis. Most researchers consider these theories at least partly emerged as a product of medical paradigms. However, they share some common features; probably the most prominent is their focus on mechanisms behind the formation of metastasis. Today, the so-called serial model is the most widely used explanation of how metastatic cells leave the primary tumor [10-17] A series of events make the invading cells able to migrate and survive in a foreign tissue. However, and surprisingly, it turns out that some metastatic lesions do not have many features in common with the primary tumor, which has led to an alternative hypothesis about metastasis; namely the parallel theory $[18,19]$. Through this explanation model it may be appropriate to consider the primary tumor as one disease, and complications incurred due to the formation of metastasis, as another, the last disease perhaps most of all influenced by mutual interactions between isolated and circulating tumor cells and their upcoming host organs. In brief, it means that micro-metastases develop differently, as a consequence of the interactions with surrounding tissue structures, and in turn, one of the potential metastases succeeds in establishing a viable solid tumor in an alien environment. In addition to the specific interaction with the host environment, the pattern of lymph- and blood flow could explain the pattern of dispersion. However, over the past decade, the so-called progression model $[20,21]$ has been widely accepted among many clinicians, due to manifestations of variation in patients histories, regardless of pathological diagnosis. This model depicted metastases as a result of consecutive mutational events, largely individual and personal, probably made possible by complex and unpredictable interactions in the organism. Interestingly, a more recent explanation for carcinoma development is focusing on the tumor's anatomical location within the organ it develops, as a key factor that can predict the pattern of spread. Such explanations are based on "the shortest path to the goal", mainly by the tumor cell's proximity to regional lymph nodes and central blood and lymphatic vessels [22]. Moreover, the very latest model proposes fusion between tumor cells and cells that naturally migrate, such as blood cells. This fusion results in a super cell with the epithelial cell's ability to proliferate, survive, and to form solid tumors, in addition to acquiring the blood cells motile capabilities [23]. There is also evidence for the existence of cancer stem cells with intrinsic cancer properties, a theory that complements the fact that many tumors are histologically heterogeneous, and that a clone with specific characteristics, after selection of a subpopulation, is able to grow invasively and in turn form metastases, in keeping with Isac Fidlers postulates that cancer occurrs as a natural selection of competitive populations of cells. However, whichever model one assumes, they are all focusing on cancer cell's ability to metastasize, as the reason why patients die. The question is therefore whether there are any mechanisms that are common to most carcinomas, which may explain their invasive behavior, regardless of theories which tries to explain why such behavior occurs. In the author's view, a three step process is able to explain the carcinoma specific behavior, namely the carcinoma cell's loss of polarity, the directional movement of isolated cells, and their ability to degrade extracellular components to create a place and space (summarized in Table 1).

\section{Carcinoma cells loose their cell polarity}

The term cellular adhesion referrs to mechanisms in which cells recognize each other and make connections, so that collections of various cells form tissues and organs. Such specialized links between cells in epithelium can be classified into three functional groups. Occluding adhesion prevent small molecules to leak from one side of the layer to the other, while anchor links connect neighboring epithelial cells to each other and to the underlying basement membrane. Communication channels lead chemical or electrical signals from one cell to another. Functional adhesion molecules can be divided into four different main families: the integrins, cadherins, selectins and immunoglobulins [24]. Reduced expression or delocalization of such adhesion is thought to play a role in the depolarization of epithelial cells, such as suppression of epithelial cadherin (adhesive link), occludin and claudine (tight junctions) and desmoplakin (desmosomes). Mechanisms involved in malignant cell adhesion have recently been reviewed [25-29]. In summary, the reorientation of depolarized epithelial cells is made possible by repeated detachment and attachment, thereby pointing out a central role for adhesion molecules as the main cellular polarity facilitators. Thus the loss of E-cadherin has been shown to correlate with invasive capacity of several malignant tumors [30], in addition to altered expression of various integrins [31]. At the same time, one can see an increased expression of neural cadherin (N-cadherin), which is a characteristic of motile cells, e.g. fibroblasts. This new situation gives rise to a mesenchymal-like architecture of the cytoskeleton, probably trigger a process where the epithelium loses its polarity, resulting in a translation from the epithelial cell morphology, to a fibroblast like cell shape.

\section{Carcinoma cells acquire motile properties}

Since the transitions from fixed cells to migratory variants are always associated with dramatic changes in cell architecture, this suggests that cell polarity proteins are likely to play important roles during epithelial cell migration. Several polarity proteins including Par3, Par6, aPKC, Scribble, Dlg and Lgl, are localized to the leading edge of migrating cells, thus playing critical roles during migration of carcinoma cells [32-34]. In addition, the cells easily break away from each other, favoring migration through the basal lamina. In turn,

\begin{tabular}{|l|l|}
\hline STEPS & CHARACTERISTICS \\
\hline Loose of cell polarity & $\begin{array}{l}\text { Loose of E-cadherin } \\
\text { Altered expression of integrins } \\
\text { Increased expression of N-cadherin }\end{array}$ \\
\hline Acquirement of motile properties & $\begin{array}{l}\text { Deregulation of polarity complexes such as Par 3, Par } 6 \text { and Scribble } \\
\text { Decrease of membrane bound } \beta \text {-catenine and increase of cytosolic } \beta \text {-catenine } \\
\text { Formation of reactive stroma through increased expression of chemokines } 35\end{array}$ \\
\hline Degradation of ECM proteins & $\begin{array}{l}\text { Increased extracellular proteolysis } \\
\text { Imbalance between proteolytic mediators, corresponding receptors, and their specific inhibitors }\end{array}$ \\
\hline
\end{tabular}

Table 1: The main three steps that characterize the spread of carcinoma cells. 
the process is demonstrated to continue in a decrease of membrane localized $\beta$-catenin, followed by an increase of cytosolic $\beta$-catenin, leading to further depolarization of cells which have lost their expression of E-cadherins. Such observations are often seen at infiltrating edges of carcinoma tumors [35-41]. In turn, migrating cells forms links between their adhesion receptors and surrounding ECM or adjacent cells, thereby forming links to their cytoskeleton. Such adhesion serve as traction points by protrusion. The movement sequence is finished by adhesion disassembly at the cell rear, followed by detachment and attachment made possible by the cytoskeleton's contractile. Taken together, such changes enable the cells to move, and in time, also form secondary metastasis.

Migration takes place along a directional gradient of soluble factors (chemotaxis) or along a gradient of immobilized factors (haptotaxis) which serve as attractants. The gradients are thought to be, at least partly produced by extracellular proteolysis of different tissue components, in addition to the overexpression of growth factor-like substances, often secreted by the fibroblasts. Such a stroma is classified as "reactive". Compounds that favor migration along a concentration gradient are designated chemokines, and they may be components of the extracellular matrix as well as growth factors. Chemokines constitute a super-family of structurally homologous heparin-binding proteins. Structurally, they are grouped into 4 families, designated CC, CXC, $\mathrm{C}$, and $\mathrm{CX} 3 \mathrm{C}$, based on the location of conserved cysteine residues near their amino-terminus [42]. CXC chemokines has been shown to play a critical role in the growth of many malignancies including lung, colorectal, pancreatic, ovarian, prostate, melanoma, brain, and renal cell $[43,44]$. For instance, stroma derived factor 1 (SDF-1), also denoted CXCL12, and its corresponding membrane receptor CXCR4, confer a more invasive phenotype on selected cancers. It is highly suggestive that SDF-1 is expressed by connective tissue and endothelial cell, as well as stromal fibroblasts, while its receptor is present in several cancer cells [45-48].

\section{Carcinoma cells are able to degrade extracellular proteins}

To invade surrounding tissue, carcinoma cells must have the ability to degrade local barriers that exist in the surrounding tissue. Thus, cancer cells of epithelial origin need to degrade structural components in the extracellular space in order to destroy barriers preventing cellular movement, mainly by the action of protein degrading enzymes. Extracellular proteolysis occurs widely in nature and serves many different purposes [48-50]. Protein degrading enzymes are classified by their catalytic mechanisms. There are four groups; serine proteases, cysteine proteases, aspartic proteases and the comprehensive group of metalloproteinases. All four categories have been shown to play roles in malignant cellular invasion. Among the four classes of proteases, the serine proteases have attracted most interest, and a number of investigators have demonstrated a strong correlation between increased PA-activity, especially the urokinase plasminogen activator (uPA) [51], and the capacity of cancer cells to invade surrounding tissue $[50,52,53]$. uPA contributes to extracellular proteolysis by activating plasminogen, an inactive plasma protein, to plasmin, a broad spectrum protease, and there is evidence that the uPA-mediated activation of plasminogen is specific to processes in which plasmin helps carcinoma cells to invade into surrounding tissue. Thus cancer cells are able to enter the blood and lymphatic vessels. Since plasmin is a broad-spectrum protease, it is supposed to be the key mediator in cancer invasion, especially by its ability to activate latent metalloproteinases. This can activate a great many protein degrading metalloproteinases, such as MMP2 (gelatinases) and membrane bound proteases such as MMP 17 (MTMMP4). In such a way, an initial uPA-mediated activation leads to a proteolytic cascade, upon which the main substance of the basal lamina, collagen type IV, dissolves [49,54]. A number of studies have shown substantial correlation between the amount of produced uPA and the cancer cell's aggressive behavior, particularly in frequent diseases such as prostate and breast cancers [55-58]. Moreover, a changed ratio between uPA and its specific inhibitor PAI-1 contributes to increased destruction of the extracellular matrix. A similar imbalance between plasmin activated metalloproteinases such as collagenase, together with cathepsins, and the broad spectrum collagenase inhibitor TIMP1 , helps to further proteolytic activity. Since uPAs binding to the cell surface is required for targeted proteolysis, expression of the receptor that binds the enzyme could be decisive for the local proteolysis $[57,59]$. In healthy tissue the balance between proteolytic enzymes, their receptors and specific inhibitors, is carefully regulated. However, such interactions are deregulated in many aggressive cancers, for example by increased expression of the uPA binding receptor (UPAR), by decrease of various protease inhibitors, and not least increased production and distribution of protein degrading enzymes [49-51,53,54,60-70].

\section{Discussion}

Despite advances in the management of many human cancers over the past few decades, improvements in survival are marginal, and the overall diagnosis and prognosis for many cancer patients still remain poor. Forthcoming studies on clinical handling of carcinomas will without doubt focus on the identification of aggressive cases with an increased risk for progressive disease and formation of metastases, and most researchers consider cancer as a multiple disease category, rather than one uniform disorder. This view is confirmed in the clinic, where metastases show great variation in clinical manifestation, depending on the primary tumor site. For example, breast cancer patients experience that disease lies dormant for many years after diagnosis, while cancer of the pancreas often is widely spread at the time of diagnosis. Deregulated cellular growth is in common to all solid tumors, which has led to the widely held interpretation that cancer is due to errors in cellular division and death mechanisms. On the other hand, a one-sided focus on cell proliferation can not explain the life-threatening aspect of advanced cancer, and the many theories that have been put forward about the hazards of the tumors, they do not primarily address cell proliferation, but rather the cells ability to grow into surrounding tissue and form distant metastasis. However, in respect to the overwhelming amount of knowledge that exists at the molecular level on cancer's cell genotype, the question is whether it is possible to precisely define today's cancer paradigm. One has found that several of the molecular changes that cancer cells have undergone, is very similar to changes that occur when the mesoderm is formed between the ectoderm and the endoderm during embryogenesis, a process that forms the basic organization of embryos. During this process, cells near the midline of the epiblast, the coming ectoderm, acquire motile properties and migrate towards the center of the embryo to form the mesoderm, which gives rise to the mesenchym. This phenomenon is often referred to as "epithelial mesenchymal transition" (EMT). In particular, the molecular changes in EMT are characterized by the fact that the connections between epithelial cells are weakened, so that the cells lose their polarity. The polarized distribution of the cytoskeleton and organelles also changes, and the cells acquire a migratory phenotype. In our opinion, the current paradigm of carcinomas is the EMT. A variety of biologically relevant processes make use of cellular movement. Examples of such processes are seen during morphogenesis, in various immune responses, in 
wound healing and not least, in cancer invasion and the formation of metastases. In non-cancerous processes, cellular migration is tightly controlled through integration of multiple signaling pathways. There are strong indications that the first local infiltration, begins with a reorientation of cell polarization, and the formation of a protrusion in the direction of the migration path.

A number of transcriptional and translational changes may play important roles in the EMT, but mechanisms that initiate these changes are unclear. Much attention has been directed against several transcription factors, especially regulators of cellular adhesion. Twist is such a transcriptional repressor, and it is found to be deregulated in cancer cells that in addition have increased their presentation of epidermal growth factor receptor. Twist is a basic helix-loophelix transcription factor that plays an important role in cellular communication and translocation during embryonic development. Other repressors of cadherin production may play roles in EMT, such as Slug and Snail. It has also been discussed whether changes in epithelial polarity may be affected by chronic inflammation. In particular, this is seen in the context of high-grade intraepithelial preneoplastic changes, which are regarded as the histological stage of the development of i.e. prostate cancer. Quite often inflammatory sites associated with these lesions are observed. It is therefore conceivable that chemotactic substances such as cytokines influence epithelial cells orientation and their migration ability. Two newly discovered cell polarity complexes may also give researchers new insights into how epithelial cells maintain their polarity, and how they change it in a malignant manner. There is also evidence that substances produced by the stroma influence the epithelium to change phenotype, especially the growth factor TGF- $\beta$ seems to play such a role. One of the best observations that confirm that the EMT is the current paradigm of cancer, is the recently published results that EMT can be reversed, probably by the action of components in the micro-cellular environment. These findings are in many ways consistent with the "seed and soil 'hypothesis, first postulated by Steven Paget. Paget's cancer paradigm compares the cancer cells with seeds, and the environment they grow in, as the soil. How whether the seeds will succeed, depends on soil. One result of such interaction may be the transformation of epithelial cells mesenchymal phenotype, to non-motile and firmly anchored cells at the metastatic site. However, and typically in the cancer field, the EMT concept appears to be fully relevant in some cases, but not explanatory in other situations, emphasizing the importance of an individual approach in future of cancer diagnosis, prognosis and treatment. In the clinic, personalized therapy may therefore be today's cancer paradigm.

\section{References}

1. Bianco R, Daniele G, Ciardiello F, Tortora G (2005) Monoclonal antibodies targeting the epidermal growth factor receptor. Curr Drug Targets 6: 275-287.

2. de Thonel A, Eriksson JE (2005) Regulation of death receptors-relevance in cancer therapies. Toxicol Appl Pharmacol 207: 123-132.

3. El-Hariry I, Pignatelli M (1997) Adhesion molecules: opportunities for modulation and a paradigm for novel therapautic approaches in cancer. Expert Opin Investig Drugs 6: 1465-1478.

4. Okegawa T, Pong RC, Li Y, Hsieh JT (2004) The role of cell adhesion molecules in cancer progression and its application in cancer therapy. Acta Biochim Pol 51: $445-457$

5. Sahai E (2005) Mechanisms of cancer cell invasion. Curr Opin Genet Dev 15: $87-96$

6. Yamazki D, Kurisu S Takenawa T (2005) Regulation of cancer cell motility through actin reorganization. Cancer Sci 96: 379-386.
7. Ikenouchi J, Matsuda M, Furuse M, Tsukita S (2003) Regulation of tight junctions during the epithelium-mesenchyme transition: direct repression of the gene expression of claudins/occludin by Snail. J Cell Sci 116: 1959-1967.

8. Klymkowsky MW, Savagner P (2009) Epithelial-Mesenchymal Transition. A Cancer Researcher's Conceptual Friend and Foe. Am J Pathol 174: 15881593.

9. Leber MF, Efferth $T$ (2009) Molecular principles of cancer invasion and metastasis. Int J Oncol 34: 881-895.

10. Al-Mulla F, Keith WN, Pickford IR, Going JJ, Birnie GD (1999) Comparative genomic hybridization analysis of primary colorectal carcinomas and their synchronous metastases. Genes Chromosomes Cancer 24: 306-314.

11. Bissig H, Richter J, Desper R, Meier V, Schraml P, et al. (1999) Evaluation of the clonal relationship between primary and metastatic renal cell carcinoma by comparative genomic hybridization. Am J Pathol 155: 267-274.

12. Hovey RM, Chu L, Balazs M, DeVries S, Moore D, et al. (1998) Genetic alterations in primary bladder cancers and their metastases. Cancer Res 58 3555-3560.

13. Kuukasjarvi T, Karhu R, Tanner M, Kahkonen M, Schaffer A, et al. (1997) Genetic heterogeneity and clonal evolution underlying development of asynchronous metastasis in human breast cancer. Cancer Res 57: 1597-1604.

14. Pandis N, Teixeira MR, Adeyinka A, Rizou H, Bardi G, et al. (1998) Cytogenetic comparison of primary tumors and lymph node metastases in breast cancer patients. Genes Chromosomes Cancer 22: 122-129.

15. Ma XJ, Salunga R, Tuggle JT, Gaudet J, Enright E, et al. (2003) Gene expression profiles of human breast cancer progression. Proc Natl Acad Sci U S A 100: 5974-5979.

16. Perou CM, Sorlie T, Eisen MB, van de Rijn M, Jeffrey SS, et al. (2000) Molecular portraits of human breast tumours. Nature 406: 747-752.

17. Porter D, Lahti-Domenici J, Keshaviah A, Bae YK, Argani P, et al. (2003) Molecular markers in ductal carcinoma in situ of the breast. Mol Cancer Res 1 : 362-375.

18. Singh SK, Hawkins C, Clarke ID, Squire JA, Bayani J, et al. (2004) Identification of human brain tumour initiating cells. Nature 432: 396-401.

19. Ramaswamy S, Ross KN, Lander ES, Golub TR (2003) A molecular signature of metastasis in primary solid tumors. Nat Genet 33: 49-54.

20. Bernards R, Weinberg RA (2002) A progression puzzle. Nature 418: 823.

21. Ling V, Chambers AF, Harris JF, Hill RP (1984) Dynamic heterogeneity and metastasis. J Cell Physiol Suppl 3: 99-103.

22. Pawelek JM (2008) Cancer-cell fusion with migratory bone-marrow-derived cells as an explanation for metastasis: new therapeutic paradigms. Future Oncol 4: 449-452.

23. Dontu G, Al-Haij M, Abdallah WM, Clarke MF, Wicha MS (2003) Stem cells in normal breast development and breast cancer. Cell Prolif 36: 59-72.

24. Davies G, Jiang WG, Mason MD (2000) Cell-cell adhesion molecules and signaling intermediates and their role in the invasive potential of prostate cancer cells. J Urol 163: 985-992.

25. Huysentruyt LC, Seyfried TN (2010) Perspectives on the mesenchymal origin of metastatic cancer. Cancer Metastasis Rev 29: 695-707.

26. Rathinam R, Alahari SK (2010) Important role of integrins in the cancer biology Cancer Metastasis Rev 29: 223-237.

27. Yilmaz M, Christofori G (2009) EMT, the cytoskeleton, and cancer cell invasion Cancer Metastasis Rev 29: 15-33

28. Friedl P, Wolf K (2009) Proteolytic interstitial cell migration: a five-step process. Cancer Metastasis Rev 29: 29-35.

29. Behmoaram E, Bijian K, Bismar TA, Alaoui-Jamali MA (2008) Early stage cancer cell invasion: signaling, biomarkers and therapeutic targeting. Fron Biosci 13: 6314-6325.

30. Cavallaro U, Christofori $\mathrm{G}$ (2004) Cell adhesion and signalling by cadherins and Ig-CAMs in cancer. Nat Rev Cancer 4: 118-132.

31. Hood JD and Cheresh DA (2002) Role of integrins in cell invasion and migration. Nat Rev Cancer 2: 91-100 
32. Huang L, Muthuswamy SK (2010) Polarity protein alterations in carcinoma: a focus on emerging roles for polarity regulators. Curr Opin Genet Dev 28: 41-50.

33. Etienne-Manneville S (2008) Polarity proteins in migration and invasion. Oncogene 27: 6970-6980.

34. Aranda V, Nolan ME, Muthuswamy SK (2008) Par complex in cancer: a regulator of normal cell polarity joins the dark side. Oncogene 27: 6878-6887.

35. Lochter A, Galosy S, Muschler J, Freedman N, Werb Z, et al. (1997) Matrix Metalloproteinase Stromelysin-1 Triggers a Cascade of Molecular Alterations That Leads to Stable Epithelial-to-Mesenchymal Conversion and a Premalignant Phenotype in Mammary Epithelial Cells. J Cell Biol 139: 1861-1872.

36. Fish EM, Molitoris BA (1994) Alterations in epithelial polarity and the pathogenesis of disease States. N Engl J Med 330: 1580-1588.

37. Lee JM, Dedhar S, Kalluri R, Thompson EW (2006) The epithelial-mesenchymal transition: new insights in signaling, development, and disease. J Cell Biol 172: 973-981.

38. Thiery JP, Sleeman JP (2006) Complex networks orchestrate epithelialmesenchymal transitions. Nat Rev Mol Cell Biol 7: 131-142

39. Hugo H, Ackland ML, Blick T, Lawrence MG, Clements JA, et al. (2007) Epithelial--mesenchymal and mesenchymal--epithelial transitions in carcinoma progression. J Cell Physiol 213: 374-383.

40. Baum B, Settleman J, Quinlan MP (2008) Transitions between epithelial and mesenchymal states in development and disease. Semin Cell Dev Biol 19: 294 308.

41. Hollier BG, Evans K, Mani SA (2009) The Epithelial-to-Mesenchymal Transition and Cancer Stem Cells: A Coalition Against Cancer Therapies. J Mammary Gland Biol Neoplasia 14: 29-43.

42. IUIS/WHO Subcommittee on Chemokine Nomenclature (2003) Chemokine/ chemokine receptor nomenclature. Cytokine 21: 48-49.

43. Zlotnik A (2004) Chemokines in neoplastic progression. Semin Cancer Biol 14 $181-185$

44. Zlotnik A (2006) Chemokines and cancer. Int J Cancer 119: 2026-2029.

45. Sun X, Cheng G, Hao M, Zheng J, Zhou X, et al. (2010) CXCL12 / CXCR4 / CXCR7 chemokine axis and cancer progression. Cancer Metastasis Rev 29: 709-722.

46. Felix AS, Edwards R, Bowser R, Linkov F (2010) Chemokines and Cance Progression: A Qualitative Review on the Role of Stromal Cell-derived Factor 1-alpha and CXCR4 in Endometrial Cancer. Cancer Microenviron 26: 49-56.

47. Taichman RS, Cooper CC, Keller ET, Pienta KJ, Taichman NS, et al. (2002) Use of the stromal cell-derived factor-1/CXCR4 pathway in prostate cancer metastasis to bone. Cancer Res 62: 1832-1837.

48. Koblinski JE, Abram M, Sloane BF (2000) Unraveling the role of proteases in cancer. Clin Chim Acta 291: 113-135.

49. Skrzydlewska E, Sulkowska M, Koda M, Sulkowski S (2005) Proteolyticantiproteolytic balance and its regulation in carcinogenesis. World J Gastroenterol 11: 1251-1266.

50. Ludwig T (2005) Local proteolytic activity in tumor cell invasion and metastasis. Bioessays 27: 1181-1191.

51. Romer J, Nielsen BS, Ploug M (2004) The urokinase receptor as a potentia target in cancer therapy. Curr Pharm Des 10: 2359-2376.

52. Jedinak A, Maliar T (2005) Inhibitors of proteases as anticancer drugs Neoplasma 52: 185-192.

53. Decock J, Paridaens R, Cufer T (2005) Proteases and metastasis: clinical relevance nowadays? Curr Opin Oncol 17: 545-550.

54. Dano K, Behrendt N, Høyer-Hansen G, Johnsen M, Lund LR, et al. (2005) Plasminogen activation and cancer. Thromb Haemost 93: 676-681.

55. Mekkawy AH, Morris DL, Pourgholami MH (2009) Urokinase plasminogen activator system as a potential target for cancer therapy. Future Oncol 9: 14871499.

56. Skogseth H, Larsson E, Halgunset J (2005) Inhibitors of tyrosine kinase inhibit the production of urokinase plasminogen activator in human prostatic cancer cells. APMIS 113: 332-339.
57. Skogseth H, Larsson E, Halgunset J (2006) Urokinase plasminogen activator receptor (UPAR) expression is reduced by tyrosine kinase inhibitors. APMIS 114: 307-313.

58. Choong PF, Nadesapillai AP (2003) Urokinase plasminogen activator system: a multifunctional role in tumor progression and metastasis. Clin Orthop Relat Res 415: 46-58.

59. Chavakis T, Kanse SM, Yutzy B, Lijnen HR, Preissner KT (1998) Vitronectin concentrates proteolytic activity on the cell surface and extracellular matrix by trapping soluble urokinase receptor-urokinase complexes. Blood 91: 23052312.

60. Mohamed MM, Cavallo-Medved D, Rudy D, Anbalagan A, Moin K, et al. (2010) Interleukin-6 increases expression and secretion of cathepsin B by breast tumor-associated monocytes. Cell Physiol Biochem 25: 315-324.

61. Cavallo-Medved D, Dosescu J, Linebaugh BE, Sameni M, Rudy D, et al (2003) Mutant K-ras regulates cathepsin B localization on the surface of human colorectal carcinoma cells. Neoplasia 5: 507-519.

62. Gocheva V, Wang HW, Gadea BB, Shree T, Hunter KE, Garfall AL, et al. (2010) IL-4 induces cathepsin protease activity in tumor-associated macrophages to promote cancer growth and invasion. Genes Dev 24: 241-255.

63. Tkachuk VA, Stepanova VV, Volynskaia EA (1998) Involvement of urokinase and its receptor in the remodelling of normal and pathological tissue. Vestn Ross Akad Med Nauk 8: 36-41.

64. Chakraborti S, Mandal M, Das S, Mandal A, Chakraborti T (2003) Regulation of matrix metalloproteinases: an overview. Mol Cell Biochem 253: 269-285.

65. Hijova E (2005) Matrix metalloproteinases: their biological functions and clinical implications. Bratisl Lek Listy 106: 127-132.

66. Jedinak A , Maliar T (2005) Inhibitors of proteases as anticancer drugs Neoplasma 52: 185-192.

67. Kondo S (2004) Tissue plasminogen activator (t-PA) and urokinase plasminogen activator (u-PA). Nippon Rinsho 62: 700-702.

68. Smith HW, Marshall CJ (2010) Regulation of cell signalling by uPAR. Nat Rev Mol Cell Biol 1: 23-36.

69. D'Alessio S, Blasi F (2009) The urokinase receptor as an entertainer of signal transduction. Front Biosci 14: 4575-4587.

70. Tang $\mathrm{CH}$, Wei $\mathrm{Y}$ (2008) The urokinase receptor and integrins in cance progression. Cell Mol Life Sci 65: 1916-1932. 